
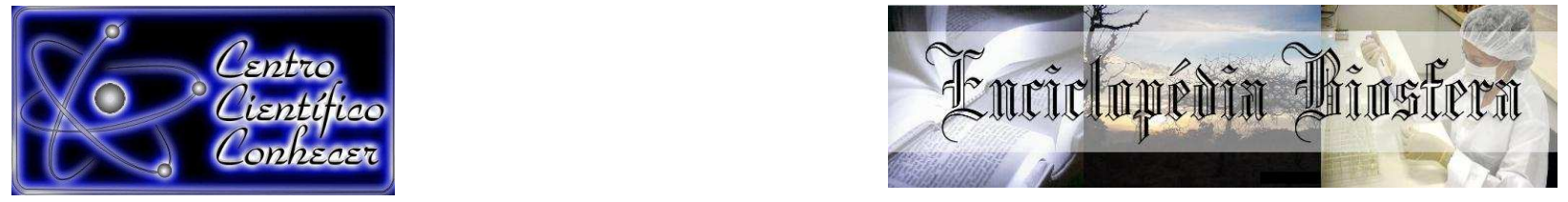

\title{
ASPECTOS AMBIENTAIS DO CÓRREGO DO BARBADO EM CUIABÁ-MT
}

\section{Raphael Antonius Luyten Garcia ${ }^{1}$, Carla Maria Abido Valentini ${ }^{2}$; Rozilaine Aparecida Pelegrine Gomes de Faria ${ }^{2}$ \\ 1.Tecnólogo em Gestão Ambiental, Instituto Federal de Mato Grosso, campus Cuiabá-Bela Vista, Cuiabá-MT, Brasil. \\ 2.Professora Doutora, Instituto Federal de Mato Grosso, campus Cuiabá-Bela Vista, Cuiabá-MT, Brasil (carla.valentini@blv.ifmt.edu.br) \\ 3. Professora Doutora, Instituto Federal de Mato Grosso, campus Cuiabá-Bela Vista, Cuiabá-MT, Brasil}

\section{Recebido em: 08/09/2015 - Aprovado em: 14/11/2015 - Publicado em: 01/12/2015 DOI: http://dx.doi.org/10.18677/Enciclopedia_Biosfera_2015_084}

\begin{abstract}
Quando efluentes sem tratamento são lançados em corpos hídricos, inúmeras mudanças são percebidas, e utilizando de parâmetros físico-químicos pode-se quantificar essas alterações. Neste trabalho objetivou-se verificar a qualidade ambiental de uma seção do Córrego do Barbado, em Cuiabá-MT, tendo como principal parâmetro o oxigênio dissolvido, determinado por análise química gravimétrica. Além de parâmetros complementares, foi realizada a coleta de espécimes e entrevistas semi-estruturadas com os moradores do entorno sobre a percepção ambiental acerca do córrego. Foram encontrados valores de oxigênio dissolvido bastante superiores ao esperado para um córrego antropizado, variando de $6,42 \mathrm{mg} \cdot \mathrm{L}^{-1}$ a $130,66 \mathrm{mg} \cdot \mathrm{L}^{-1}$. Espécimes de peixes identificados mostraram a seletividade decorrente da poluição e como a relação dos moradores com o córrego mudou ao longo do tempo. Quanto à utilização do método gravimétrico para quantificação de oxigênio dissolvido, é necessário que sejam feitas adaptações na metodologia para corpos d'água.
\end{abstract}

RESUMO

PALAVRAS-CHAVE: córregos urbanos, oxigênio dissolvido, poluição hídrica

\section{ENVIRONMENTAL ASPECTS OF CÓRREGO DO BARBADO IN CUIABÁ -MT}

\begin{abstract}
When untreated effluents are released into water bodies, numerous changes are perceived, and it is possible to quantify those using physical and chemical parameters. This study aimed to verify the environmental quality of a section of Barbado Stream in Cuiaba-MT, using as the main parameter dissolved oxygen, determined by gravimetric chemical analysis. As well as additional parameters, specimens were collected and semi-structured interviews with people living around the stream were performed about their environmental perception. Dissolved oxygen values found were far superior to the expected for an anthropized stream, ranging from $6.42 \mathrm{mg} \cdot \mathrm{L}^{-1}$ to $130.66 \mathrm{mg} \cdot \mathrm{L}^{-1}$. Identified specimens of fish showed selectivity resulting from pollution and how the relationship of the residents with the stream
\end{abstract}


changed over time. Regarding the use of the gravimetric method for quantification of dissolved oxygen, adaptation is necessary in the methodology for water bodies.

KEYWORDS: urban streams, dissolved oxygen, water pollution

\section{INTRODUÇÃO}

A história humana mostra que a origem e desenvolvimento de inúmeras cidades se deram ao lado de margens fluviais, aproveitando suas águas para diversas funcionalidades, inclusive como destinação de rejeitos orgânicos e inorgânicos. O crescimento populacional advindo da urbanização tem sido acelerado nas últimas décadas, e como consequência da expansão urbana desordenada, surgem problemas, principalmente em relação a infraestrutura precária e a degradação ambiental.

Da água de abastecimento que entra no sistema urbano, uma boa parte, após utilização, transforma-se em esgoto. De maneira geral o esgoto doméstico é composto por matérias orgânicas e inorgânicas nas formas dissolvida, coloidal e em suspensão. Não havendo o tratamento adequado das águas residuárias, levantamse questões sobre os possíveis impactos ao meio ambiente e os consequentes riscos á saúde humana (PHILLIP JUNIOR, 2005).

Parte da crise ambiental tem inicio nas áreas urbanas, decorrentes de três principais fatores: o crescimento populacional, o crescimento da demanda por recursos e o crescimento da quantidade de resíduos gerados e descartados no meio ambiente, ocasionando, principalmente, a poluição das águas (MAZZER, 2004). O objetivo estratégico da gestão ambiental é o de conciliar a obtenção de resultados econômicos e financeiros com a preservação dos recursos naturais sujeitos ao seu controle e a sua influencia (ANJOS JUNIOR, 2011).

Cuiabá, capital do estado de Mato Grosso, não é exceção dos problemas ocasionados pela ocupação urbana e pela má gestão ambiental. Seu crescimento acelerado, por volta dos anos 80 , caracterizou-se pelas ocupações irregulares em áreas de preservações ambientais (APPs) ao longo das margens dos rios e córregos, a exemplo do que ocorreu com o córrego do Barbado. Sem atender o devido planejamento e cumprimento das legislações urbanas, teve como um de seus principais impactos ambientais o lançamento de esgoto sem tratamento em seus corpos hídricos (BRITTO \& SILVA, 2006; MENEZES FILHO \& AMARAL, 2014).

$A$ análise da água de um manancial pode evidenciar o uso inadequado do solo, os efeitos do lançamento de efluentes, suas limitações de uso e seu potencial de autodepuração (ALMEIDA et al., 2006), e um dos parâmetros mais importantes de caracterização da qualidade de água no meio ambiente é o Oxigênio Dissolvido OD.

ARAUJO et al (2004), afirmaram que, devido à sua importância, o OD é amplamente utilizado como principal parâmetro da qualidade de água e serve para determinar o impacto de poluentes sobre corpos d'água, pois é um dos mais importantes fatores no desenvolvimento de qualquer planejamento na gestão de recursos hídricos.

PINTO et al., (2010) salientaram que o oxigênio dissolvido é um excelente indicador de qualidade das águas e que conjuntamente com parâmetros coadjuvantes, como condutividade elétrica, $\mathrm{pH}$, turbidez e temperatura do ar e da água é possível obter-se dados no campo a baixo custo e tempo real.

Diante dos problemas apresentados, e pensando na possibilidade de tornar a medida de OD com custo mais acessível, este trabalho teve como objetivo verificar a qualidade ambiental de uma seção do Córrego Barbado, através de análises do 
oxigênio dissolvido na água por um método alternativo gravimétrico (FERREIRA et al., 2004). Também foram usados parâmetros físico-químicos complementares e registros da percepção dos moradores do entorno.

\section{MATERIAL E MÉTODOS}

\section{Área de estudo}

O Município de Cuiabá, capital do estado de Mato Grosso, está situado na unidade geomorfológica classificada como Depressão Cuiabana ( $15^{\circ} 10^{\prime}$ a $15^{\circ} 50^{\prime} \mathrm{S}$ e $54^{\circ} 50^{\prime}$ a $58^{\circ} 10^{\prime} O$ ), com clima do tipo Aw segundo a classificação de Köppen, ou seja, tropical semi-úmido, com índice pluviométrico anual varia de 1250 a $1500 \mathrm{~mm}$ (MAITELLI, 1994). Possui pequena amplitude térmica, exceto em fenômenos de friagem, com temperatura média anual de $26,8^{\circ} \mathrm{C}$, e m édia das máximas de $42^{\circ} \mathrm{C}$ e médias das mínimas de ${ }^{\circ} 5^{\circ} \mathrm{C}$ (FRANCO et al., 2013).

Em Cuiabá existem mais de 20 córregos de drenagem que recebem o esgoto doméstico e industrial. A Microbacia do Córrego do Barbado, localizada estritamente na área urbana de Cuiabá-MT, na porção centro-leste da cidade, tem como principal curso d'água o Córrego do Barbado (FIGURA 1). O Barbado percorre aproximadamente $8,95 \mathrm{~km}$ de extensão, desde sua nascente no Parque Massairo Okamura, até sua foz, no Rio Cuiabá (VENTURA, 2011).

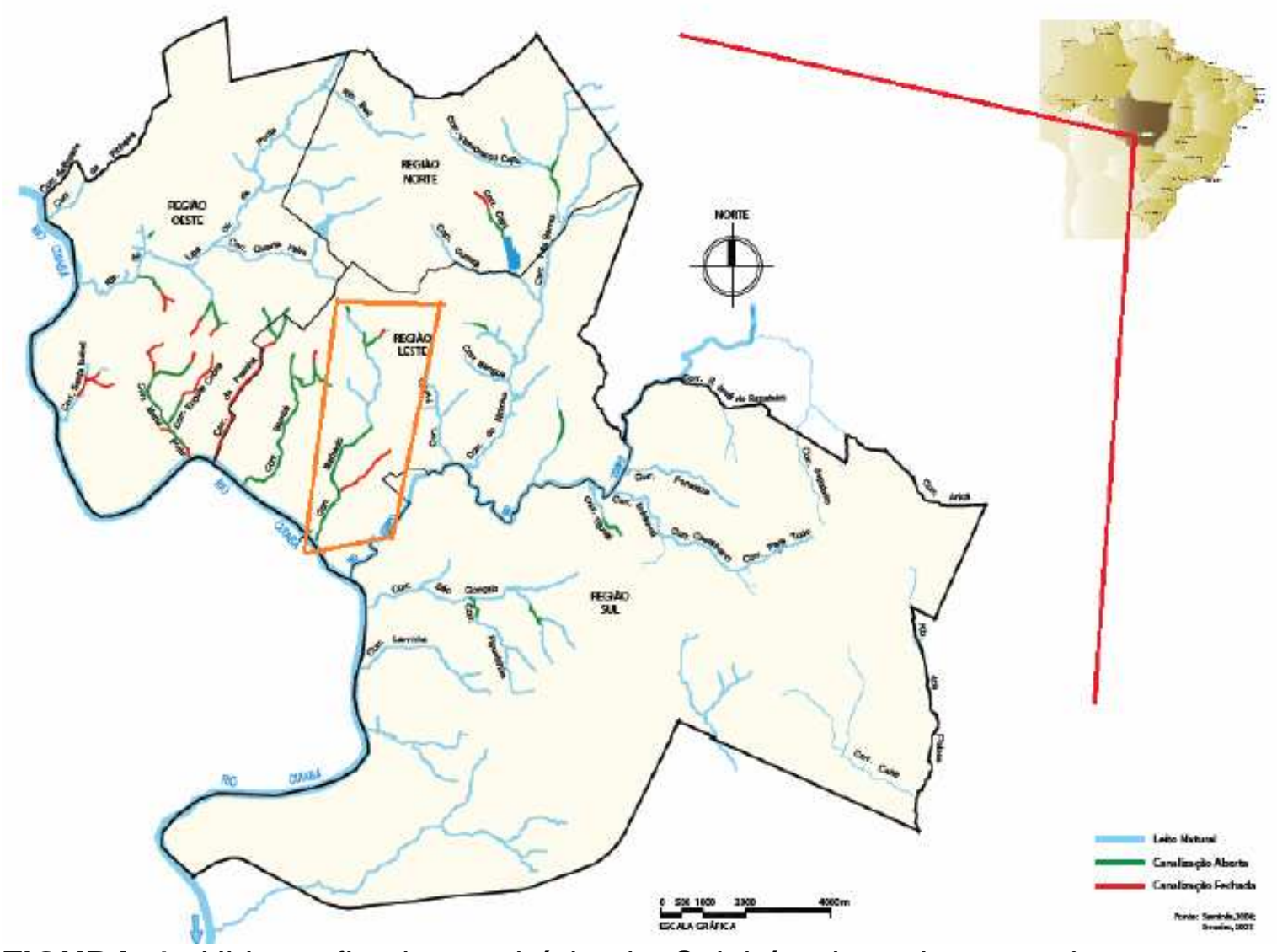

FIGURA 1. Hidrografia do município de Cuiabá adaptado, com destaque para o córrego do Barbado. Adaptado da Smenifes, 2006/ Smafes, 2007 Perfil sócio econômico de Cuiabá, vol III, /IPDU, 2007). Fonte: KREISCHER et al (2012). 


\section{Local de coleta}

O ponto de coleta de água para as análises do córrego do Barbado (FIGURA 2) foi uma seção do alto curso do córrego, que se localiza no bairro Bela Vista (153' $43,20^{\prime \prime}$; $56^{\circ} 03^{\prime} 59,10^{\prime \prime} \mathrm{O} ; 193 \mathrm{~m}$ ). O local foi escolhido, porque dos 22 bairros que possuem mais de $50 \%$ de sua área localizada na microbacia do Barbado, o Bela Vista é o mais populoso, com 3.985 habitantes em uma área de 29 hectares, com moradores de menor renda média e baixa escolaridade, além de concentrar um número expressivo de ocupações irregulares (IPDU, 2007).

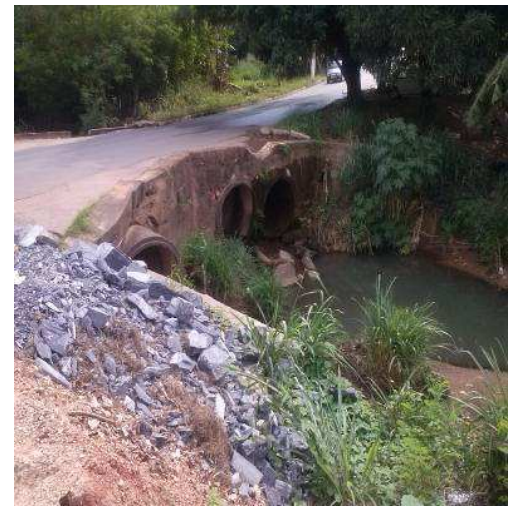

(A)

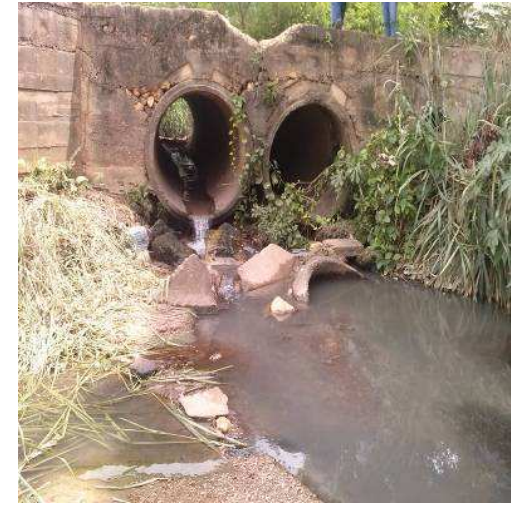

(B)

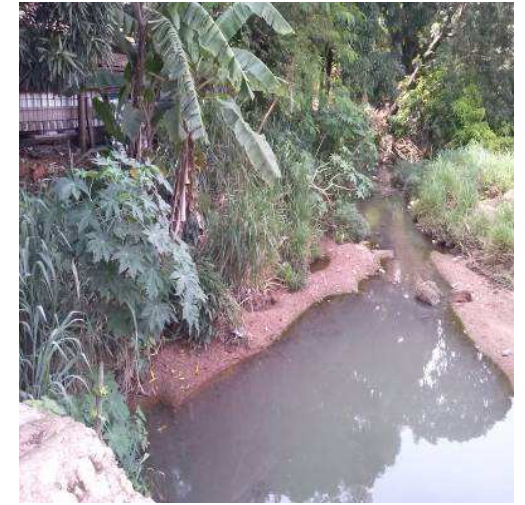

(C)

FIGURA 2. Local de coleta do córrego do Barbado: A: visto da rua do Bairro Bela Vista que passa sobre o córrego; B: destaque para a queda de água das tubulações à montante do ponto de coleta; C: Vegetação ciliar ao redor do ponto de coleta (Fonte: AUTORES, 2013).

\section{Metodologia}

\section{Parâmetros físico-químicos}

O córrego do Barbado possui nascente e foz dentro do município, portanto o monitoramento é de competência do órgão ambiental municipal. A resolução CONAMA (357/2005) determina que caso o rio não possua um enquadramento, deve-se obedecer aos padrões para corpos hídricos de Classe 2.

As coletas foram realizadas semanalmente no período matutino. Os parâmetros físico-químicos analisados no laboratório de físico-química do IFMT, campus Cuiabá-Bela Vista, ao longo do ano de 2013, de abril à novembro, estão descritos na Tabela 1.

As Coletas de águas do ponto amostrado foram realizadas de acordo com a NBR 9898 (ABNT, 1987) utilizando um balde graduado. A transferência da amostra para as cinco garrafas (pet) vazias de 500 mililitros (branco, três para determinação de OD e uma para demais análises físico-químicas) foi feita por meio de um tubo de látex. As amostras foram transportadas em caixa térmica até o Laboratório de Águas do IFMT campus Cuiabá-Bela Vista, para análise imediata (Figura 3) 


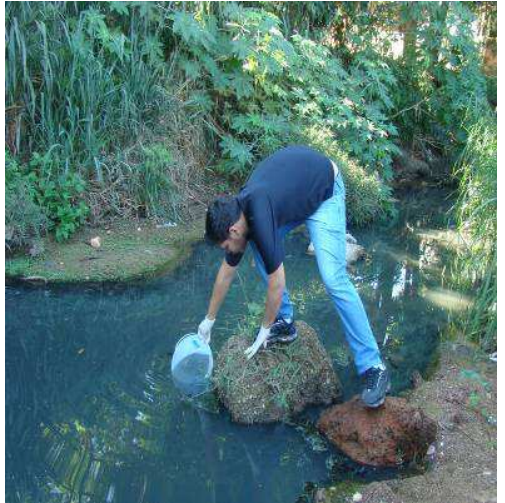

(A)

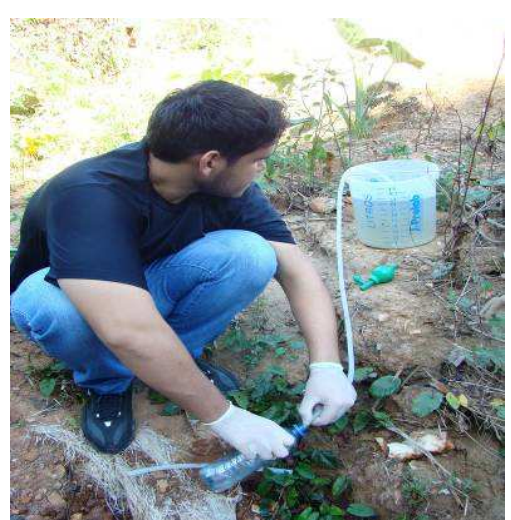

(B)

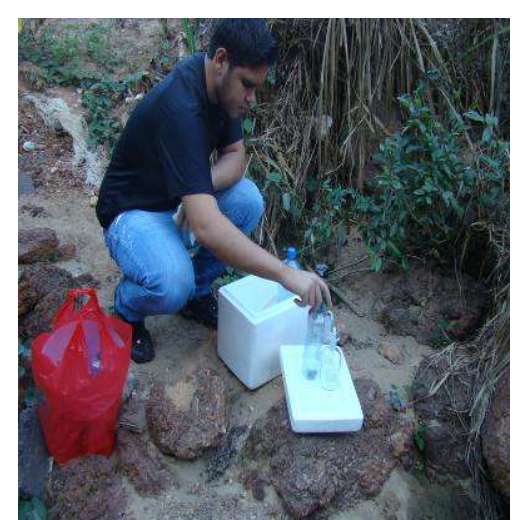

(C)

FIGURA 3. Coleta de amostras: A: Coleta com balde graduado; B: Transferência de amostra; C: Armazenamento para transporte (Fonte: AUTORES, 2013).

Importante ressaltar que nesta pesquisa a determinação de oxigênio dissolvido foi realizada utilizando-se o método gravimétrico proposto por FERREIRA et al. (2014) e não os métodos mais habituais de determinação de OD: Método titulométrico de Winkler modificado pela azida sódica ou método eletrométrico de medida direta de OD por sensor específico para oxigênio.

TABELA 1- Parâmetros físico-químicos analisados nas amostras do córrego do Barbado.

\begin{tabular}{|c|c|c|}
\hline Parâmetros & $\begin{array}{l}\text { Unidades de } \\
\text { medida }\end{array}$ & $\begin{array}{c}\text { Método de } \\
\text { quantificação/instrumento }\end{array}$ \\
\hline $\begin{array}{l}\text { Oxigênio dissolvido } \\
\text { (OD) }\end{array}$ & $\mathrm{mg} \cdot \mathrm{L}^{-1}$ & $\begin{array}{l}\text { Gravimétrico (Ferreira et al., } \\
\text { 2004)* }\end{array}$ \\
\hline Sólidos totais & $\mathrm{mg} \cdot \mathrm{L}^{-1}$ & Gravimétrico \\
\hline Temperatura & $\stackrel{\circ}{ } \mathrm{C}$ & $\begin{array}{l}\text { Termômetro analógico } \\
\text { Modelo: Total immersion } \\
\text { Fabricante: Allafrance/help }\end{array}$ \\
\hline $\mathrm{pH}$ & UC & $\begin{array}{l}\text { Colorimétrico } \\
\text { Colorímetro de bancada } \\
\text { Modelo: Nessler-quanti } 200 \\
\text { Fabricante: Policontrol } \\
\text { Eletrométrico } \\
\text { PHmetro de bancada } \\
\text { Modelo: MPA-210/MPA-210p } \\
\text { Fabricante : MS Tecnopon } \\
\text { Eletrométrico }\end{array}$ \\
\hline Condutividade & $\mu \mathrm{S} . \mathrm{cm}^{-1}$ & $\begin{array}{l}\text { Condutivímetro de bancada } \\
\text { Fabricante: MS Tecpon }\end{array}$ \\
\hline
\end{tabular}

${ }^{*} \mathrm{O}$ método gravimétrico alternativo proposto por FERREIRA et al.(2004), baseia-se na reação de uma massa de ferro presente palha de aço com o OD presente em determinado volume de água coletada dando origem a um precipitado, a ferrugem $\left(\mathrm{Fe}_{2} \mathrm{O}_{3}\right)$, posteriormente pesado.

Para a execução do método gravimétrico de OD (FERREIRA et al., 2004), pesou-se em balança de precisão, três pedaços de palha de aço de 0,375 $\mathrm{g}$ cada. 
Com o auxílio de um bastão de vidro, cada um dos três pedaços foram introduzidos em uma garrafa PET de água mineral vazia com capacidade volumétrica de $500 \mathrm{~mL}$.

Com as garrafas inclinadas em aproximadamente $30^{\circ}$, por meio do uso de tubo látex colocou-se a água coletada como descrito anteriormente. Após a transferência das amostras, as garrafas permaneceram abertas por 15 minutos e depois foram fechadas e observadas por cinco dias.

Após o período de observação, as garrafas foram abertas e o sólido de cor marrom avermelhado (óxido ferrico) foi recolhido por filtração. O papel de filtro foi colocado em estufa (110 $\left.{ }^{\circ} \mathrm{C}, 1 \mathrm{~h}\right)$, arrefecido em des secador e pesado antes e após a filtragem.

Por meio da estequiometria da reação de formação do óxido férrico (equação a seguir), foi calculado o OD da água das garrafas. Os resultados foram expressos nas unidades $\mathrm{mg} \cdot \mathrm{L}^{-1}$.

$$
2 \mathrm{Fe}_{(\mathrm{s})}+3 / 2 \mathrm{O}_{2(\mathrm{~g})} \rightarrow \mathrm{Fe}_{2} \mathrm{O}_{3(\mathrm{~s})}
$$

Como a metodologia proposta FERREIRA et al. (2004) superestima o valor de OD com um erro relativo de $8,4 \%$ em relação ao método eletrométrico, os valores encontrados foram ajustados para se descontar esse erro.

A principal adaptação realizada no método de determinação de OD proposto por FERREIRA et al. (2004) foi a realização de um branco da amostragem quando se coleta água de córrego ou rio, porque é necessário quantificar separadamente os sólidos contidos nessas águas e descontar este valor de todas as amostras, de forma que não sejam quantificados como óxido férrico.

O método gravimétrico, além de ter um baixo custo, preconiza uma menor quantidade de operações laboratoriais, o que implica, em química analítica, em um menor erro operacional e sistemático.

\section{Percepção hidroambiental dos moradores}

Foram realizadas 19 entrevistas semi-estruturadas com os moradores do Bairro Bela vista que residem há mais de 20 anos no entorno do ponto de coleta durante o mês de novembro de 2013. Os entrevistados assinaram um Termo de Anuência Prévia, livre e esclarecido, aceitando participar das entrevistas.

\section{Coleta de espécimes}

Com o auxilio de uma tarrafa, foram coletadas na época de chuva, espécimes de peixes, que foram identificadas pela professora Doutora Sandra Mariotto, no Laboratório de Genética e Evolução da Universidade Federal do Estado de Mato Grosso (UFMT).

\section{RESULTADOS E DISCUSSÃO}

\section{Temperatura do ar e da água}

A temperatura do ar e da água são totalmente dependentes uma da outra, pois a temperatura atmosférica interfere diretamente na da água. A alteração na temperatura da água causa interferência nas características químicas, afetando o pH e a saturação dos gases, consequentemente os níveis de OD. 
Na FIGURA 4 são apresentadas a precipitação, umidade relativa média e temperaturas médias máximas e mínimas registradas em Cuiabá e na FIGURA 5 são apresentadas a temperatura média mensal da água e do ar no ponto de coleta.

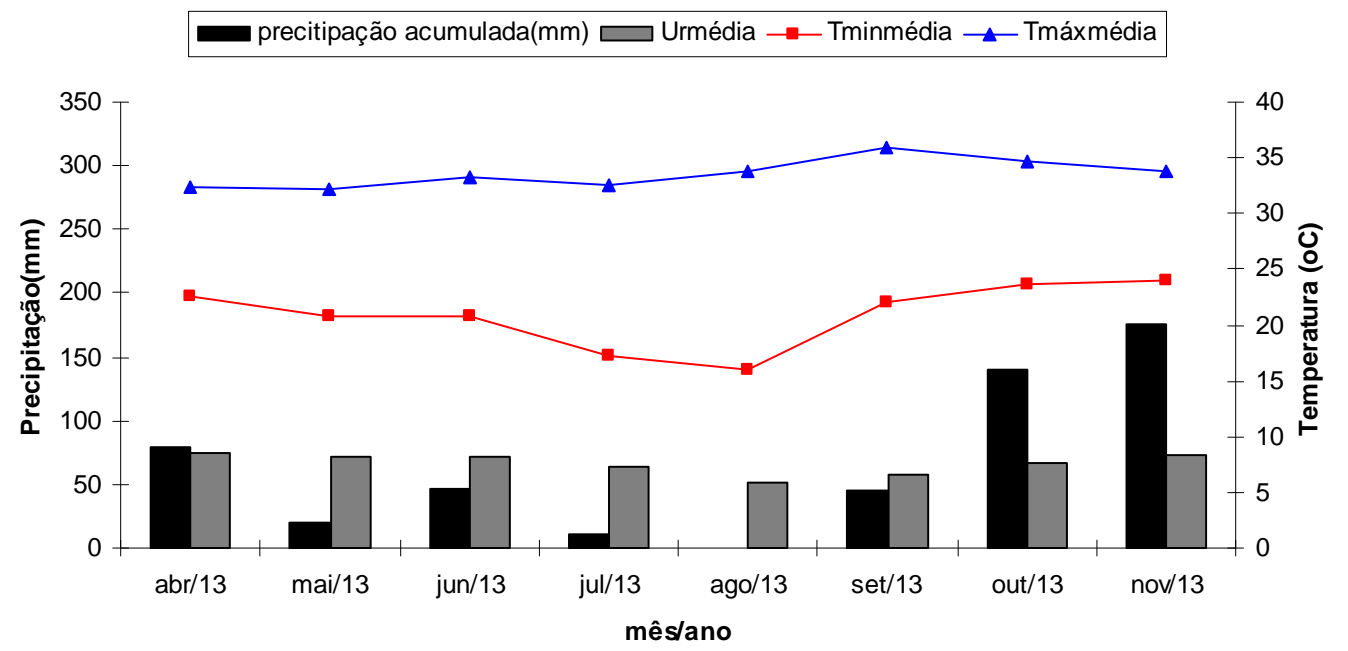

FIGURA 4. Precipitação, umidade relativa média e temperaturas médias máxima e mínima para Cuiabá de abril de 13 a novembro de 2013.(Fonte: Valores obtidos do Banco de Dados Meteorológicos para Ensino e Pesquisa)http://www.inmet.gov.br/projetos/rede/pesquisa/)

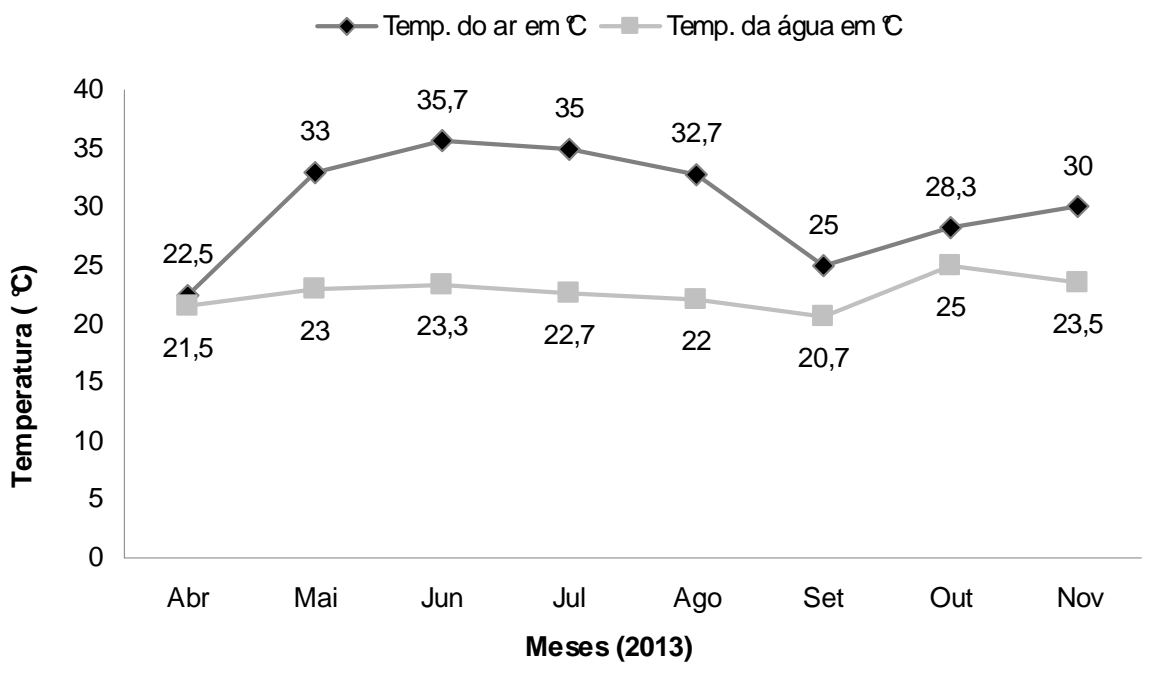

FIGURA 5. Média mensal da temperatura do ar e da água no ponto de coleta do córrego do Barbado ente os meses de abril e novembro de 2013.

A temperatura do ar que oscilou entre $22,5^{\circ} \mathrm{C}$ e $35,7^{\circ} \mathrm{C}$, e tendo em vista que a temperatura média em Cuiabá gira em torno dos $26,8^{\circ} \mathrm{C}$, os meses de maio, junho, julho, agosto, outubro e novembro de 2013 apresentaram temperaturas acima ENCICLOPÉDIA BIOSFERA, Centro Científico Conhecer - Goiânia, v.11 n.22; p.249 
da média anual. Vale lembrar que as coletas foram feitas no início do período matutino, horário em que as temperaturas são mais amenas.

A temperatura da água variou entre $20,7^{\circ} \mathrm{C}$ e $2^{\circ} \mathrm{C}$, e nos períodos de estiagem mais acentuada, entre maio e agosto, observou-se uma grande amplitude térmica entre as temperaturas do ar e água. Apesar do corpo hídrico no ponto de coleta ser lêntico e de pouca profundidade, o que corroboraria para que a temperatura da água seja próxima à do ar, a explicação para o observado pode ser o fato de uma das margens possuir vegetação ciliar (FIGURA 2C), o que ajuda na conservação térmica do ponto de amostragem. Outra hipótese é a estratificação térmica, que pode ocorrer pelo fato de se formar, devido às diferentes temperaturas, camadas d'água com várias densidades, que em si já formam uma barreira física, impedindo que se misturem se a energia do vento não for suficiente. Dessa forma o calor não se distribui uniformemente, criando a condição de estabilidade térmica (SOUZA et al., 2012).

\section{Oxigênio dissolvido}

O oxigênio dissolvido é um parâmetro extremamente importante, pois é necessário para a respiração da maioria dos organismos que habitam o meio aquático. Um rio considerado limpo, em condições normais, apresenta normalmente, de 8 a $10 \mathrm{mg} \cdot \mathrm{L}^{-1}$, que pode variar em função da temperatura e pressão (CARMOUZE, 1994). Níveis significativamente abaixo dos valores de saturação, frequentemente ocorrem em águas superficiais poluídas. Considerando que peixes e a maioria da vida aquática sofrem com a falta de oxigênio, a determinação de OD é uma das principais analises em levantamentos de impactos ambientais como a poluição orgânica e a eutrofização. Para resolução 357/05 do CONAMA, os valores de OD devem ser superiores a $4 \mathrm{mg} . \mathrm{L}^{-1}$

Utilizando-se o método gravimétrico foram encontrados os seguintes valores médios dos meses analisados, apresentados na FIGURA 6.

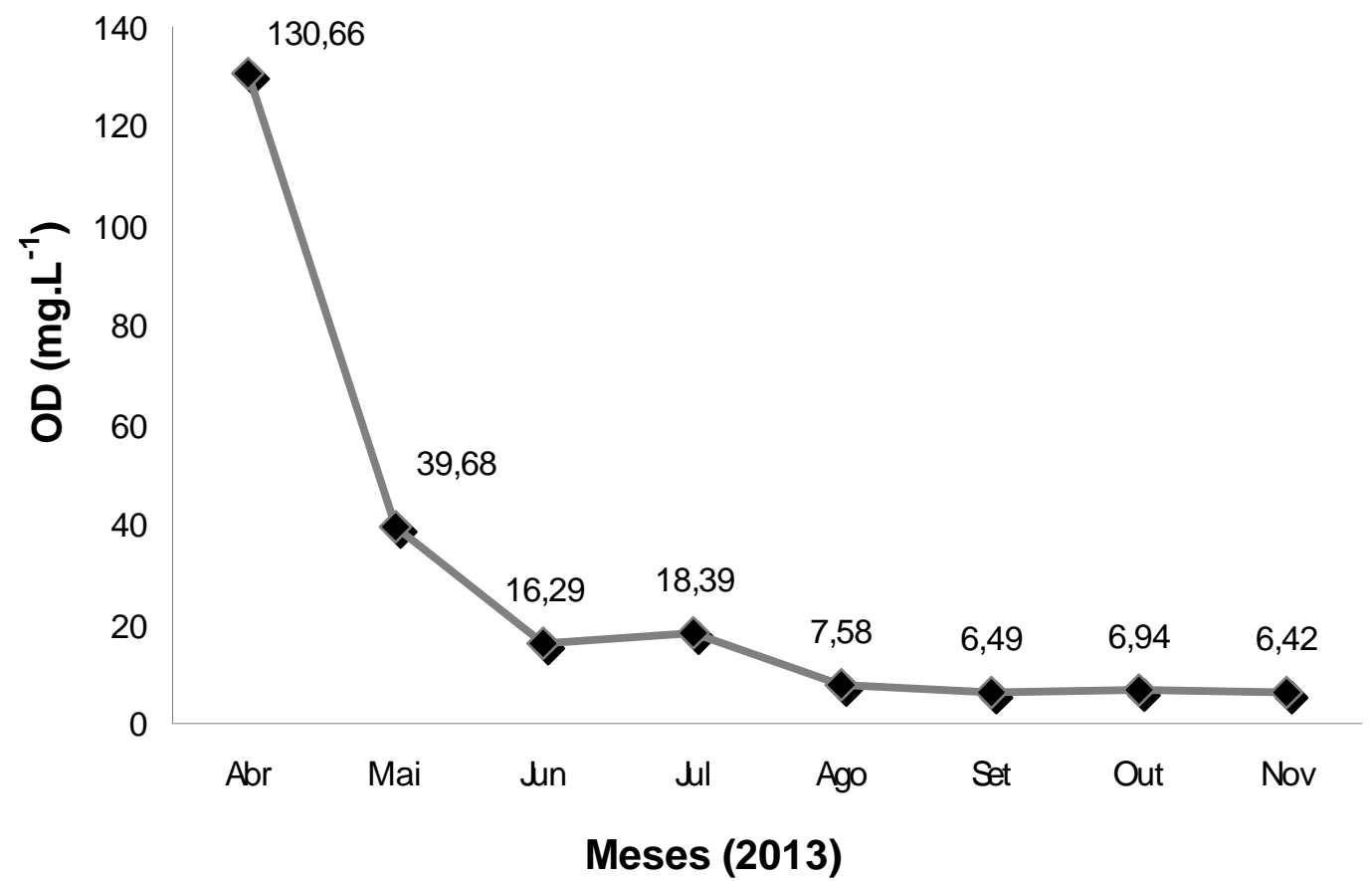

FIGURA 6 Média mensal de Oxigênio dissolvido na água no ponto de coleta do córrego do Barbado. 
Os meses de setembro, outubro e novembro apresentaram médias de 6,49 $\mathrm{mg} \cdot \mathrm{L}^{-1} ; 6,94 \mathrm{mg} \cdot \mathrm{L}^{-1}$ e $6,42 \mathrm{mg} \cdot \mathrm{L}^{-1}$. Enquanto maio e agosto apresentaram valores entre $39,68 \mathrm{mg} \cdot \mathrm{L}^{-1}$ e $7,58 \mathrm{mg} \cdot \mathrm{L}^{-1}$. O mês de abril surpreende com o valor de 130,66 $\mathrm{mg} \mathrm{L}^{-1}$. Considerando que o corpo hídrico estudado possui muitos indícios de impactos ambientais, apresentou valores de OD muito além do esperado, até para rios em perfeito estado de conservação.

Contudo, águas eutrofizadas podem apresentar valores altos de OD evidenciando um estado de supersaturação. Esse fenômeno ocorre principalmente em ambientes aquáticos de baixa velocidade, apresentando crostas verdes de algas nas margens e superfície, como ocorre na seção estudada (FIGURAS 7A e 7B). Isso porque o oxigênio liberado pelas algas através da fotossíntese segue para a atmosfera influenciando nos altos níveis de OD encontrados nas amostras (SILVA et al., 2014). Nesse processo, a luz atua como fonte de energia e o dióxido de carbono dissolvido na água, como fonte de carbono. Como resultado do processo fotossintético, oxigênio também é produzido. O oxigênio em excesso é liberado para a atmosfera, não permanecendo disponível por muito tempo para decompor a matéria orgânica.

A eutrofização consiste no aumento excessivo de nutrientes na água, podendo ser causada por drenagem de fertilizantes agrícolas, águas pluviais de cidades, detergentes, resíduos de minas, conservas alimentícias, drenagem de dejetos humanos; fontes artificiais de fósforo e nitrogênio (BARRETO et al., 2013). SMITH \& SCHINDLER (2009) citaram que um dos efeitos potenciais da eutrofização é o crescimento da biomassa de algas e a diminuição da diversidade de espécies, ou seja, essa afloração acaba totalmente com o equilíbrio natural do corpo hídrico (ANA, 2011).

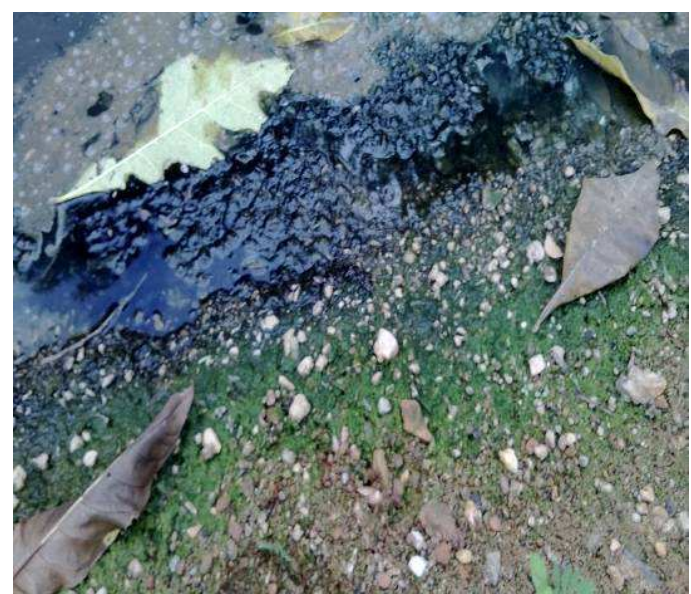

A

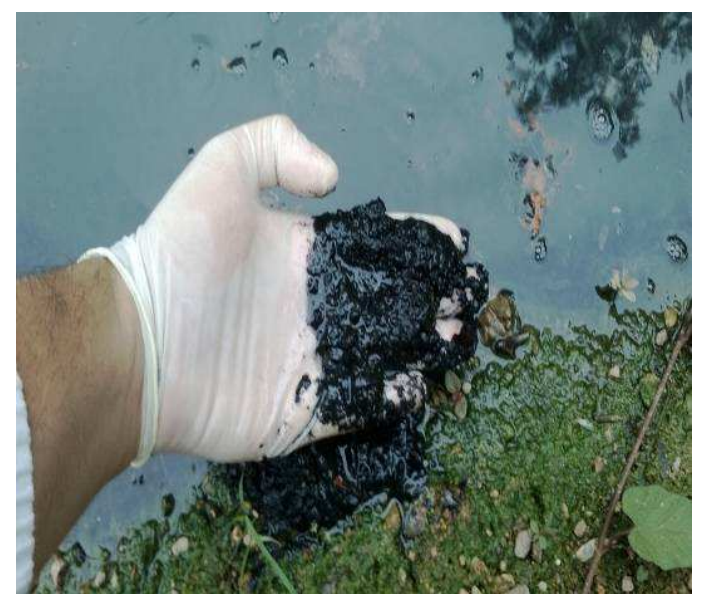

$\mathrm{B}$

FIGURA 7. Margem com acumulo de algas (A) e Resíduos da eutrofização (B)

(Fonte: fotos de Garcia no local de coleta, 2013)

KREISCHER et al., (2012) monitoraram o OD no mesmo ponto do córrego do Barbado entre setembro de 2010 e agosto de 2011 utilizando o método eletrométrico através de um oxímetro portátil, obtendo valores abaixo do estabelecido pela Resolução CONAMA (357/2005). Na Tabela 2 é apresentada a comparação entre resultados de OD em mg. $\mathrm{L}^{-1}$ obtidos por KREISCHER et al (2012) no mesmo ponto de coleta, e do presente estudo (2013). 
TABELA 2 Valores de OD em mg. $\mathrm{L}^{-1}$ da seção estudada do córrego Barbado em 2011 e em 2013.

\begin{tabular}{l|c|c}
\hline Meses & $(\mathbf{2 0 1 1})^{\star}$ & $\mathbf{( 2 0 1 3 )}$ \\
\hline Abril & 3,5 & 130,66 \\
Maio & 2,6 & 39,68 \\
Junho & 1,8 & 16,29 \\
Julho & 2,7 & 18,39 \\
Agosto & 1,8 & 7,58 \\
Setembro & 5,1 & 6,49 \\
Outubro & 7,1 & 6,94 \\
Novembro & 11,4 & 6,42 \\
\hline
\end{tabular}

*(Fonte: KREISCHER Et al., (2012)

A diferença é explicada pelo fato do teor de OD depender de vários fatores, como a pressão atmosférica, a temperatura, nível de precipitação, salinidade, sólidos totais, compostos orgânicos, etc. A junção desses fatores faz com que os valores de OD mudem diariamente. FELLENBERG (1980) explica que a desejada decomposição dos materiais orgânicos em água e $\mathrm{CO}_{2}$ têm como conseqüência também um consumo maior de oxigênio, ou seja, um maior lançamento de esgotos pode ter ocorrido no período de coleta do trabalho de KREISCHER et al., (2012).

Chama a atenção também a observação de HVITVED-JACOBSEN (1982), ao descrever o efeito de descargas orgânicas nas concentrações de oxigênio dissolvido de um pequeno rio. Sua pesquisa indicou que somente $4 \%$ da matéria orgânica lançada foi biologicamente degradada em uma extensão de $5 \mathrm{~km}$. Em comparação, aproximadamente $35 \%$ da matéria orgânica foi removida por sedimentação para o leito do rio, e o restante foi carreado para jusante do trecho estudado.

Vale ressaltar, que no mesmo intervalo de meses, a temperatura da água no trabalho de KREISCHER et al., (2012) foi superior ao presente trabalho com diferenças em até $10^{\circ} \mathrm{C}$, com média de $26,5^{\circ} \mathrm{C}$, enquanto nesse a média foi de $22,7^{\circ} \mathrm{C}$. De acordo com a relação de Arrhenius, a cinética de uma dada reação química pode ser dobrada aumentando-se a temperatura em 10 'C. Consequentemente, diversas transformações ou efeitos relacionados à água serão favorecidos pelo aumento da temperatura da água que levam ao aumento da concentração de substâncias dissolvidas na água, mas também à diminuição da concentração de gases dissolvidos. Este último ponto é muito importante com respeito ao oxigênio dissolvido na água (DELPHA et al., 2011).

\section{Sólidos totais}

Todas as impurezas da água, com exceção dos gases dissolvidos, cooperam para a carga de sólidos recorrente nos corpos hídricos.

Segundo TUCCI (2008), os sólidos totais dão um bom indicio de nível de ocupação e estágio de desenvolvimento de uma bacia hidrográfica. Os dois tipos principais de sólidos são os sedimentos gerados pela erosão do solo, em razão do efeito da precipitação e do sistema de escoamento, e os resíduos sólidos produzidos pela população. A soma desses dois componentes é chamada de sólidos totais.

Na FIGURA 8 são apresentadas as médias mensais de sólidos totais. 


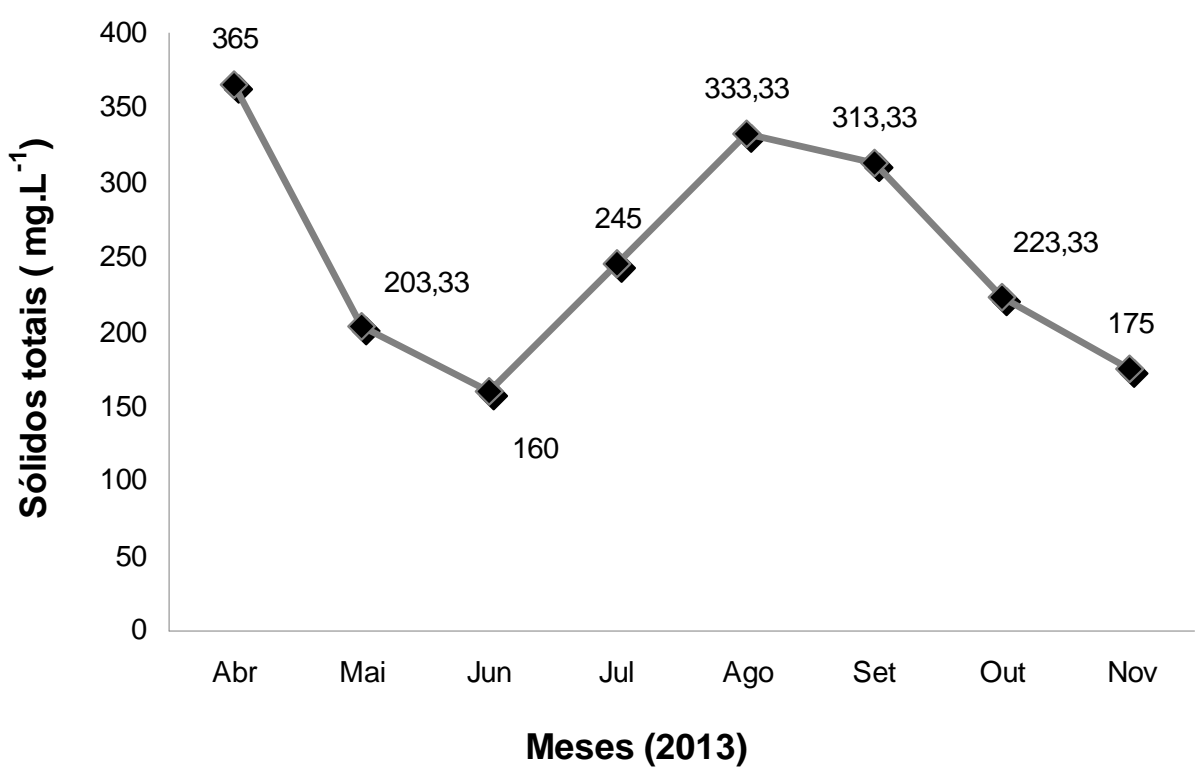

FIGURA 8 Média mensal de sólidos totais na água no ponto de coleta no córrego do Barbado.

Os meses de abril, agosto e setembro apresentaram valores acima de 300 $m g . L^{-1}$ e os meses de maio, junho, julho, outubro e novembro apresentaram valores abaixo de $300 \mathrm{mg}^{-\mathrm{L}^{-1}}$. De acordo com a Resolução CONAMA 357/2005, para enquadramento do corpo hídrico nas Classes 1, 2 e 3 a concentração de sólidos totais não deve ultrapassar $500 \mathrm{mg} \cdot \mathrm{L}^{-1}$. Portanto, os valores obtidos tanto para o período da estiagem, quanto para o período de chuvas não ultrapassaram o limitado pela legislação.

O comportamento dos sólidos totais é semelhante ao da turbidez, variável com a qual se relaciona. Os valores refletem a condição local, com aumento em locais de maior poluição (ALMEIDA \& SCHWARZBOLD, 2003). Comparando com o estudo de KREISCHER et al., (2012), observou-se que os maiores valores de turbidez coincidiram com os maiores valores obtidos de sólidos totais para esse estudo.

Importante ressaltar que conforme dados do Instituto de Planejamento e Desenvolvimento Urbano (2007), a disposição de resíduos no Bairro Bela Vista se dá por coleta de serviços de limpeza urbana (799), por coleta por caçamba (5), queima (42), terrenos baldios (39), rio (7) e outros (10). Os quintais de muitas casas se dão na beira do leito do córrego, assim como os terrenos baldios, o que corrobora para que muitos sedimentos sejam advindos de resíduos sólidos.

Diversos estudos demonstraram que a disposição inadequada de resíduos sólidos é responsável pela contaminação das fontes superficiais de água e principalmente do lençol freático (PORTO et al., 2004; VELOZO, 2006; ATHAYDE JÚNIOR et al., 2008; SHINZATO et al., 2012;). No entanto, o conhecimento sobre a duração do processo de contaminação ambiental por estes depósitos de resíduos ainda não está consolidado (SINGH et al., 2009).

\section{Cor}

A cor da água é um importante parâmetro, pois é atribuída a diversos tipos de compostos dissolvidos na água, desde matéria orgânica, íons metálicos e materiais ENCICLOPÉDIA BIOSFERA, Centro Científico Conhecer - Goiânia, v.11 n.22; p.253 
sintéticos A cor obtida nas coletas foi a cor aparente (FIGURA 9), diferente da cor verdadeira que é obtida após a eliminação das partículas em suspensão. A legislação CONAMA (357/2005) trabalha com base na cor verdadeira, sendo assim não se deve comparar os resultados obtidos com a legislação.

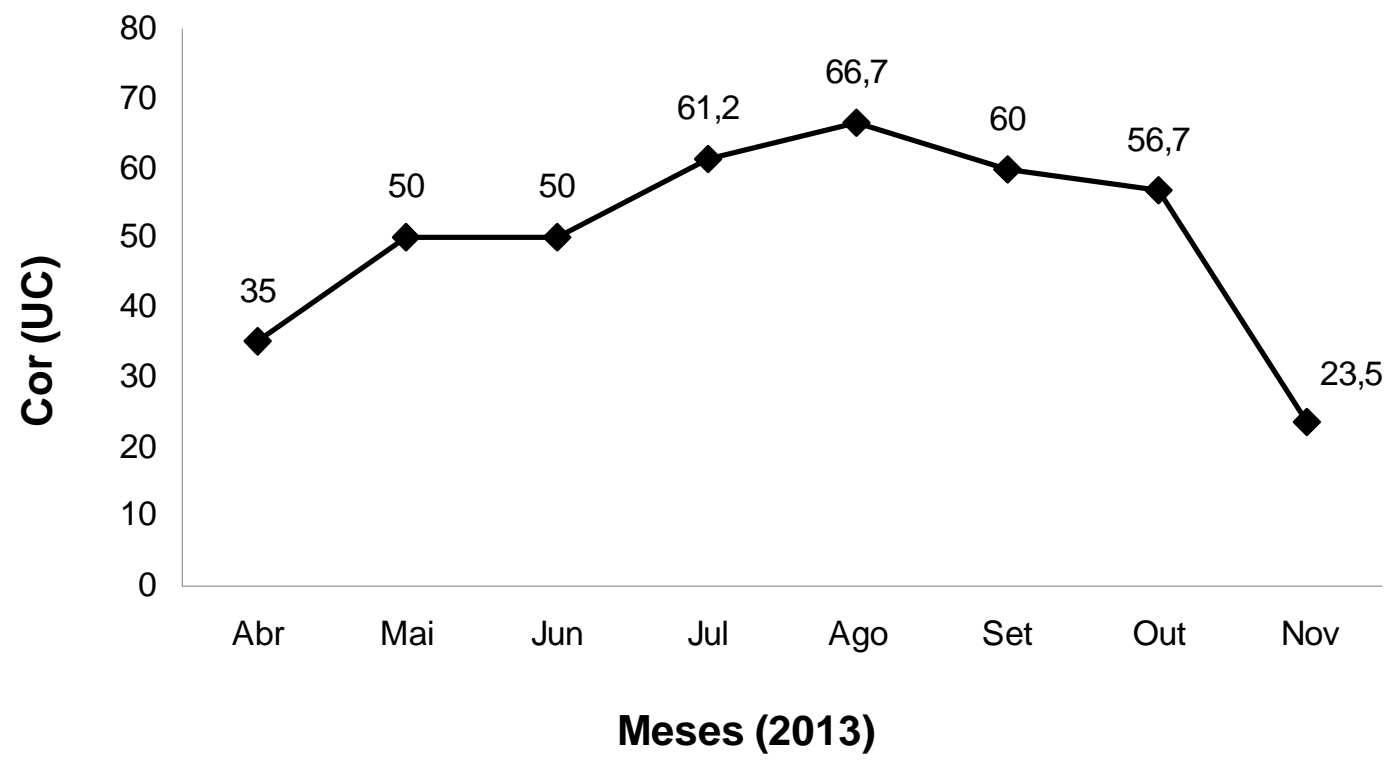

FIGURA 9 Média mensal da cor da água no ponto de coleta do córrego do Barbado.

O mês de novembro apresentou o valor médio de 23,5 UC, que pode ser explicado pelo fato das chuvas terem diluído os solutos, fazendo com que a cor seja menos perceptível. Em agosto e setembro, tempo de seca, os valores foram respectivamente $66,7 \mathrm{UC}$ e $60 \mathrm{UC}$, que se devem a quantidade concentrada de soluto dos efluentes.

$\mathrm{pH}$

$\mathrm{O} \mathrm{pH}$ é um parâmetro utilizado para expressar a alcalinidade ou a acidez de uma amostra. Importante para manutenção da vida aquática, é fato que uma mudança brusca no pH pode acarretar a morte dos seres aquáticos. Também fornece indícios do grau de poluição em um ecossistema aquático.

Na FIGURA 10 é apresentado o pH médio mensal das amostras coletadas. 


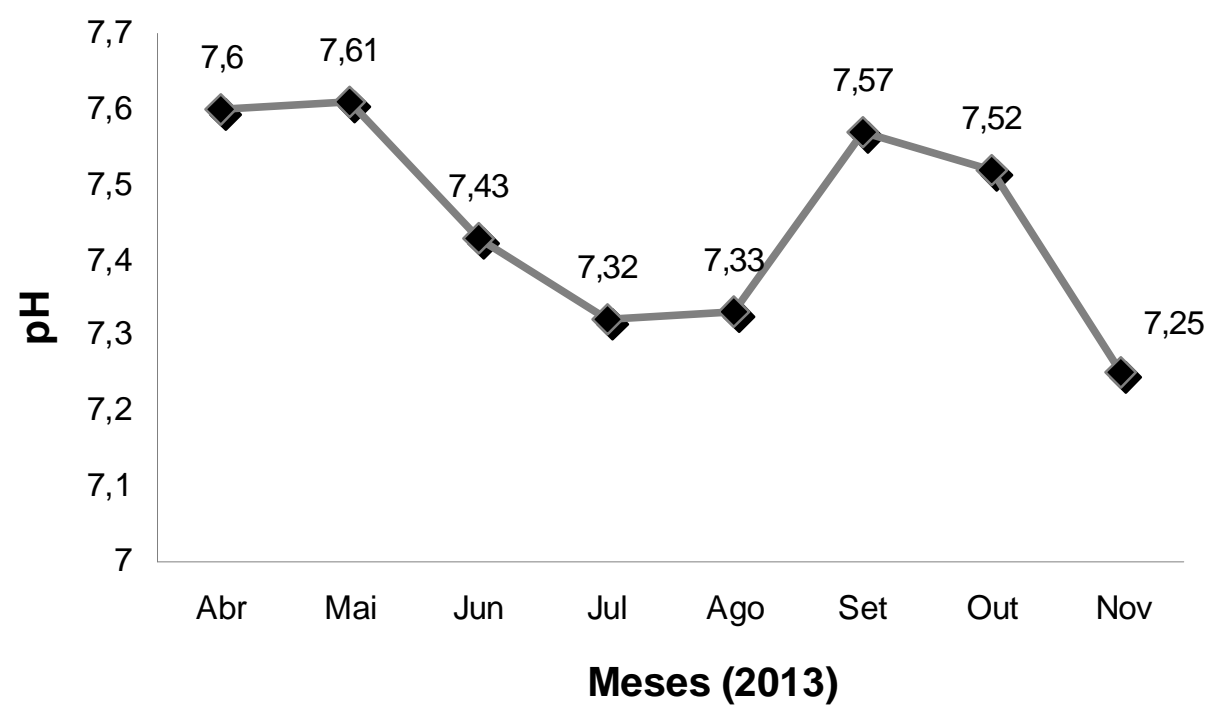

FIGURA 10 Média mensal do pH da água no ponto de coleta do córrego do Barbado.

$\mathrm{O} \mathrm{pH}$ variou entre 7,25 (novembro) e 7,61 (maio), sendo que ao longo das coletas não houve uma variação bruta dessa variável. Esses valores estão em conformidade com a legislação CONAMA (357/2005), enquadrado em águas de classe 2. Comparando aos valores de KREISCHER, GONÇALVES \& VALENTINI (2012), os valores foram próximos, porém neste estudo o $\mathrm{pH}$ sempre foi acima de 7 , ou seja, ligeiramente alcalino.

É importante salientar que valores de $\mathrm{pH}$ afastados da neutralidade podem afetar a vida aquática. Valores elevados de $\mathrm{pH}$ podem estar associados à proliferação de algas (CARVALHO et al., 2000), como observado no local de coleta. Portanto, este parâmetro é diretamente influenciado pelas taxas de fotossíntese do ecossistema, pois quando esta se eleva, favorecida pelo enriquecimento da água por nitrogênio e fósforo, o pH da água tende a aumentar, ou seja, tornar-se mais alcalino em decorrência da diminuição das concentrações de gás carbônico na água (WETZEL, 2001).

\section{Condutividade}

A Condutividade expressa a capacidade de condução de corrente elétrica de sais dissolvidos e ionizados presentes na água. A avaliação da condutividade elétrica permite indicar a presença de sais, minerais ácidos e contaminantes lançados nos sistemas aquáticos, ou seja, pode ser utilizada como parâmetro de avaliação de qualidade. Porém, apesar de dar uma boa indicação das modificações na composição da água, especialmente na sua concentração mineral, não fornece nenhuma indicação de quais são e as quantidades relativas dos vários componentes (ESTEVES, 2011; DIAS \& POTT, 2013).

Na FIGURA 11 é apresentada a média mensal de condutividade nos meses de estudo. 


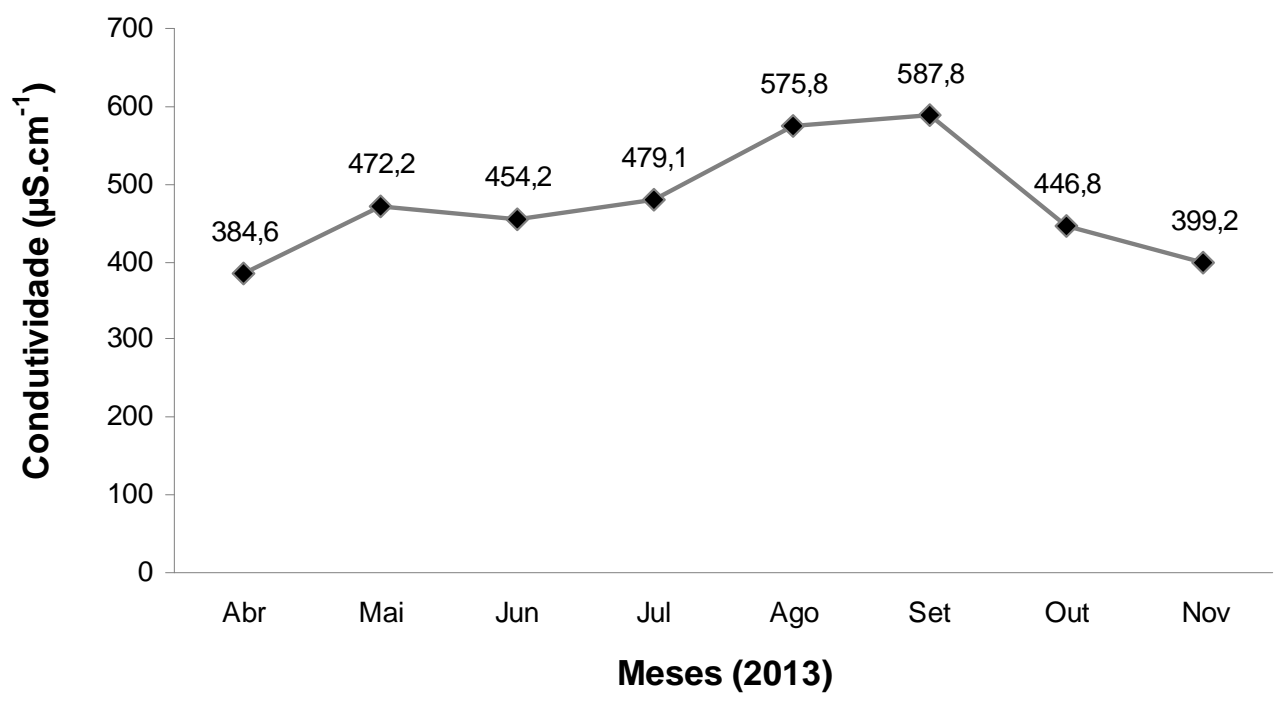

FIGURA 11 Média da condutividade da água no ponto de coleta do córrego do Barbado.

A Resolução CONAMA 357/2005 não determina valor específico para esta variável, porém quando as concentrações ultrapassarem $100 \mu \mathrm{S} . \mathrm{cm}^{-1}$, o ambiente pode estar impactado por ações antrópicas com possibilidade de entrada de esgoto no ambiente (CETESB, 2009 citado por BUZELLI \& CUNHA-SANTINO, 2013).

Comparando os valores desse trabalho ao estudo de KREISCHER et al., (2012), observou-se que em todos os meses, houve aumento importante da condutividade, sendo que ao comparar o mês de julho de 2011 e julho de 2013, percebeu-se que o valor praticamente quadruplicou.

\section{Percepção ambiental dos moradores do entorno do ponto de coleta}

A importância da percepção da população sobre o córrego presente em suas vidas mostra uma realidade interessante levando em conta o tempo em que residem próximos ao Barbado. Moradores mais antigos, residentes no local há mais de 20 anos, demonstram um conhecimento maior relacionado à representação do Córrego em suas vidas, mostrando respeito e nostalgia perante esse.

Quando questionados sobre como surgiu o bairro, foram unânimes em dizer que o inicio da comunidade se deu através de "grilagem". Porém dois moradores mais antigos explicaram como o Bela Vista passou de grilo para bairro:

"... Há 30 anos ou mais o "grilo" surgiu pela necessidade de moradia para as pessoas vindas do êxodo rural". (J. S.)

“... A gestão Dante foi a responsável por fornecer as escrituras". (A. F.)

Com o tempo o córrego do Barbado mudou drasticamente. Antigamente o córrego evidenciava a qualidade de vida aos moradores, pois tinha um importante papel para quem o utilizava. Dentre as atividades citadas pelos moradores estão: $16 \%$ lavagem de roupas, $42 \%$ lazer/banho, $16 \%$ pesca, $16 \%$ garimpo.

“... A água era limpa, ótima para pescar, tomar banho, era lazer para a família”. (D. M.) 
Contudo, essa interação da população local com o córrego do Barbado mudou negativamente nos dias atuais. $89 \%$ dos entrevistados dizem ser impossível a utilização do córrego para qualquer fim. Porém uma moradora afirmou que utiliza o córrego do Barbado para um único fim:

\section{“... jogo lixo quando a prefeitura não vem recolher”. (M. S.)}

Outro aspecto que demonstra a face atual do Barbado é referente aos problemas que a poluição traz para a residência e saúde dos moradores. Quando questionados, a maioria frisa três problemas graves: Mosquito $26 \%$, mau cheiro $52 \%$ e transmissão de doenças $36 \%$, sendo de destaque a fala de dois moradores.

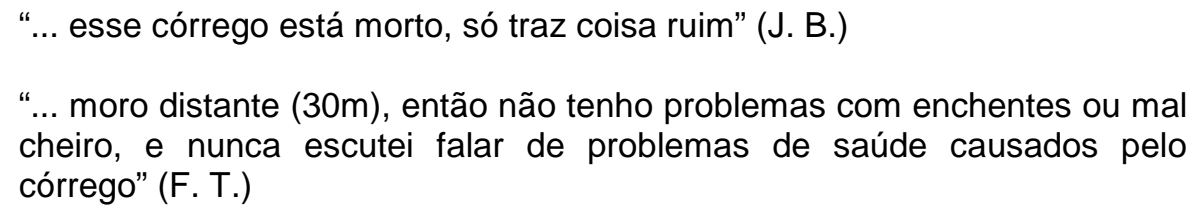

A última frase demonstra que algumas pessoas preferem fechar os olhos para a problemática como um todo, mesmo que a poluição do Barbado, sendo um problema real para a maioria das famílias. Em relação à rede de coleta de esgoto, segundo os moradores, $57,4 \%$ das casas entrevistadas possuem a coleta de esgoto através de tubulação e $36,6 \%$ não possuem acesso à rede de coleta de esgoto.

$$
\text { “...o esgoto de minha casa vai direto para o córrego” (J. S.) }
$$

De acordo com Instituto de Planejamento e Desenvolvimento Urbano (2007), o descarte de efluentes no Bairro Bela Vista se dá por rede geral ou fluvial (689), fossas sépticas (102), fossas rudimentares (64), valas (11), córrego(14) e outros(1). É notória no local e na fala dos moradores a presença de descarte clandestino de esgotos diretamente no córrego.

Quando a ocupação ocorre por meio de invasão, instala-se aí uma sequência de problemas ambientais, que vão desde o arranjo espacial desordenado das moradias, até a existência de esgotos a céu aberto e lançamento de resíduos sólidos em locais impróprios dentro da própria comunidade (CRISPIM et al., 2013). Essa falta de controle habitacional às margens de córregos urbanos e outras áreas que deveriam ser preservadas gera a poluição hídrica, e não há investimentos palpáveis em programas governamentais e socioambientais (SILVA \& JARDIM, 2007).

A vida animal e vegetal também faz parte das características do córrego, logo afetam diretamente a população. Animais são sempre citados pelos moradores, desde tartarugas, gambás, lagartos, sapos, peixes, aves, insetos, cobras, ratos e jacarés. Os bichos mais comuns são peixes e insetos. Os insetos, principalmente o mosquito transmissor da dengue, o Aedes aegypti, é muito presente dentro das reclamações da população. Alguns entrevistados lembraram-se do caso de uma família com três mortes resultantes do vírus da dengue.

Os esgotos também contribuem para proliferação de insetos, moscas, mosquitos, roedores e outros vetores de doenças. Diarréia, verminose, teníase, esquistossomose e cólera são entre outras as doenças mais comuns derivadas da disposição inadequada de esgotos (CARVALHO \& OLIVEIRA, 2003). 
Os peixes são pouco vistos, e são os de menor porte que conseguem viver na água rasa e poluída. Foram identificados na coleta de espécimes do local: peixes da Ordem Siluriformes, família Callichthyidae, espécie Corydoras sp, que ocupam ambientes lênticos e suportam águas com pouco oxigênio, pois podem respirar pelo intestino, capturando ar na superfície como fazem alguns cascudos Hypostomus affinis; e também da Ordem Cyprinodontiformes, família Poelicidae, espécie Pamphoichthys hasemani (Henn) - peixes diminutos, de ambientes lênticos que se alimentam de larvas de insetos (FIGURA 12).

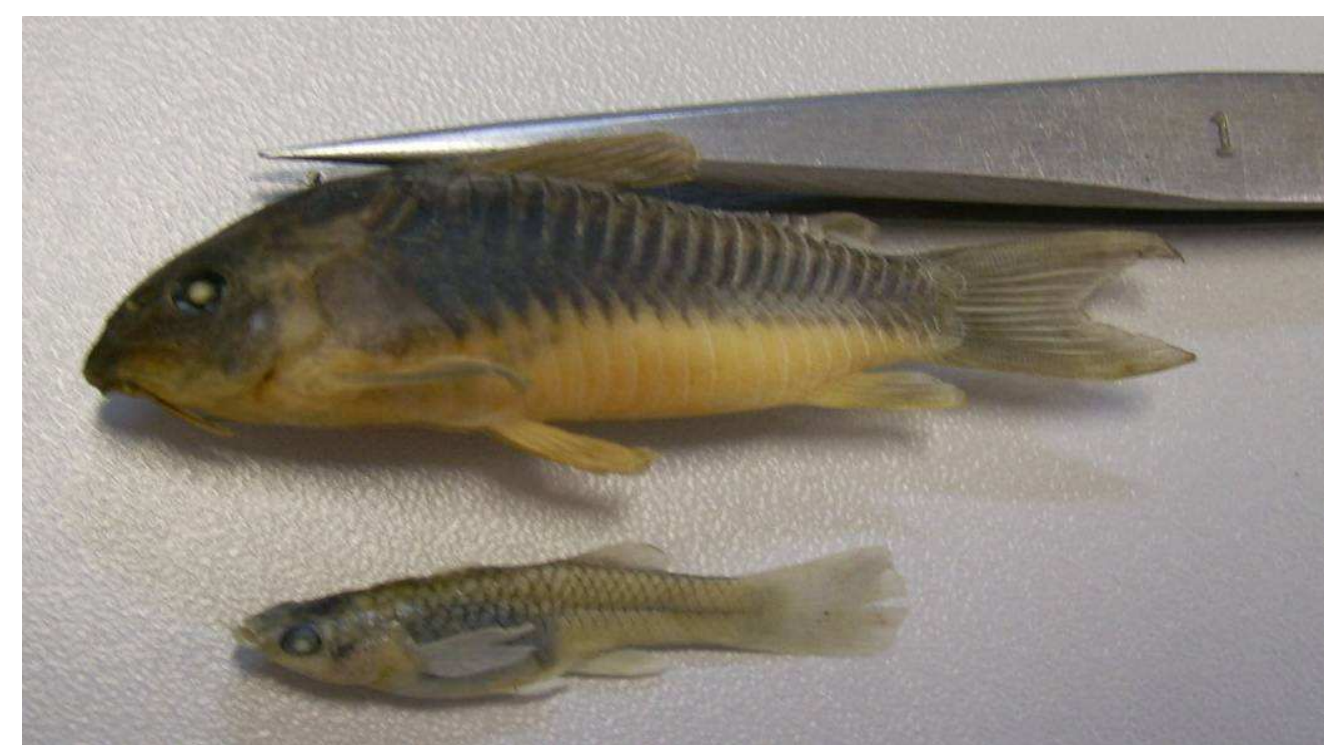

FIGURA 12- Espécies de peixes coletadas no córrego do Barbado. (Fonte: SANDRA MARIOTTO, 2013).

Os ecossistemas em condições de perturbações possuem baixa diversidade de espécies e elevado número de indivíduos da mesma espécie. A poluição é seletiva para as espécies, somente aquelas bem adaptadas às novas condições ambientais sobrevivem (VON SPERLING, 2005).

Questionados sobre as plantas que crescem naturalmente ao redor do córrego, moradores informaram alguns tipos: mamoeiro, bananeira, tomateiro, melão-são-caetano, mangueira. Outros foram bem sucintos em suas respostas: "mato".

Mais uma vez se percebe a nostalgia que o córrego trás para alguns moradores, quando o senhor J. S. foi questionado sobre algum beneficio da mata ao redor do córrego ele logo lembrou: "o pessoal antigo utilizava as plantas daqui para fazer remédios, hoje em dia não dá mais".

As matas ciliares são alvos de degradação constate devido ao fato de não haver planejamento em áreas urbanas; as casas são comumente construídas margeando os corpos hídricos (ARAÚJO et al., 2004). Essa foi uma situação observada no local de coleta. O quintal dos moradores se confunde com as margens do córrego e eles plantam árvores que possam gerar frutos para seu consumo. Ademais são plantas invasoras e gramíneas que formam uma vegetação ciliar e abrigam a fauna sinatrópica.

Os rios integram tudo o que acontece nas áreas de entorno, considerando-se o uso e ocupação do solo. Assim, suas características ambientais, especialmente as 
comunidades biológicas, fornecem informações sobre as conseqüências das ações do homem (CALLISTO et al., 2001).

Desta forma, o monitoramento deve ser visto como um processo essencial à implantação dos instrumentos de gestão das águas, já que permite a obtenção de informações estratégicas, acompanhamentos das medidas efetivas, atualização do banco de dados e atualização das decisões (MAGALHÃES JUNIOR, 2000).

\section{CONCLUSÕES}

O trabalho possibilitou a identificação da relação existente entre os moradores mais antigos do bairro Bela Vista e o Córrego do Barbado. O Córrego que antigamente era de grande importância na vida da comunidade, representa hoje uma ameaça para seu ambiente e saúde.

A análise dos parâmetros físico-químicos do córrego do Barbado, não demonstrou que o mesmo está poluído, se levarmos em consideração apenas os valores dos parâmetros na margem "permitida por lei", porém é nítida visualmente a degradação do leito, a descarga de efluentes sem tratamento na calha do córrego, os resíduos nas margens, a eutrofização da água, e a baixa diversidade de espécimes na seção pesquisada.

Quanto à utilização do método gravimétrico proposto por FERREIRA et al. (2004) para quantificação do OD, é necessário que seja feita uma adaptação para amostras de águas de córregos e rios utilizando-se um branco para descontar-se os sólidos totais presentes na água.

\section{AGRADECIMENTOS}

Agradecemos à profa Dra. Sandra Mariotto pela coleta e identificação de espécimes de peixes e aos alunos do curso superior de Tecnologia em Gestão Ambiental do IFMT campus-Cuiabá-Bela Vista, pela ajuda durante o trabalho, especialmente na coleta de dados das entrevistas: Ana Cristina Costa, Gabriela Victória Corrêa, Vitor Schmidt, Laudyana Souza e Francielly Oliveira.

\section{REFERÊNCIAS}

ALMEIDA, M. A. B.; SCHWARZBOLD, A. Avaliação sazonal da qualidade das águas do Arroio da Cria Montenegro, RS com aplicação de um índice de qualidade de água (IQA). Revista Brasileira de Recursos Hídricos, v. 8, n. 1, p. 81-97, 2003.

ANA, Agência Nacional de Águas (Brasil). Cuidando das águas: soluções para melhorar a qualidade dos recursos hídricos. Programa das Nações Unidas para o Meio Ambiente. Brasília, 2011. 154p.

ANJOS JUNIOR, A. H. Gestão estratégica do saneamento. 1. Ed. Manole. São Paulo, 2011. 187p.

ARAUJO, M. M.; LONGHI, S. J.; BARROS, P. L. C.; BRNA, D. A.: Caracterização da chuva de sementes, banco de sementes do solo e banco de plântulas em Floresta Estacional Decidual Ripária Cachoeira do Sul, RS, Brasil. Scientia Florestalis, n.66, p.128-141, 2004. 
ARAÚJO, S. C. S.; SALLES, P. S. B. A.; SAITO, C. H. Desenvolvimento tecnológico e metodológico para medição entre usuários e comitês de bacia hidrográfica. Brasília: Departamento de Ecologia. Editora da UNB, p.9-24.2004.

ASSOCIAÇÂO BRASILEIRA DE NORMAS TĖCNICAS. NBR 9898: preservação e técnicas de amostragem de efluentes líquidos e corpos receptores - Procedimento. Rio de Janeiro, 1987.

ATHAYDE JÚNIOR, G. B.; NÓBREGA, C. C.; GADELHA, C. L. M.; SANTANA, N. C. B.; COSTA, M. D. Principais usos da água do rio Sanhauá na área de influência do antigo lixão do Roger: proposta de revisão de enquadramento do rio. Revista Ambiente e Água, v. 3, n. 3, p. 128- 142, 2008.

BARRETO, L.V.; BARROS, F. M.; BONOMO, P.; ROCHA, F. A.; AMORIM, J. S. Eutrofização em rios brasileiros. Enciclopédia Biosfera, v.9, n.16; p. 2165-2179, 2013.

BRASIL Conselho Nacional do Meio Ambiente. Resolução Conama 357/2005. Enquadramento dos Corpos Hídricos Superficiais no Brasil. Governo Federal, Brasilia. Publicada no DOU ํo 53, de 18 de março de 2005, Seção 1, p. 58 63.2005.

BRITTO, A. L.; SILVA, V. A. C. Viver às margens dos rios: uma análise da situação dos moradores da favela Parque Unidos do Acari. In: COSTA, L.M.S.A. (org.) Rios e Paisagens Urbanas em cidades brasileiras. Rio de Janeiro: Viana \& Mosley: Ed. PROURB. 2006. p.57 - 76 .

CALLISTO, M.; MORETTI, M.; GOULART, M. Macro invertebrados bentônicos como ferramenta para avaliar a saúde de riachos. Revista Brasileira de Recursos Hídricos, v 6, n. 1, p.71-82, 2001.

CARMOUZE, J. P. O metabolismo dos ecossistemas aquáticos: fundamentos teóricos, métodos de estudo e análises químicas. São Paulo: Edgar Blucher: FAPESP, 1994. $253 \mathrm{p}$.

CARVALHO, A. R.; SCHLITTLER, F. H. M.; TORNISIELO, V. L. Relações da atividade agropecuária com parâmetros físicos químicos da água. Química Nova, v. 23, n. 5, p. 618-622, 2000.

CARVALHO, R. A ; OLIVEIRA, M. C. V. Princípios básicos de saneamento do meio. São Paulo. 3 ed. Editora SENAC. São Paulo. 2003. 56p.

COMPANHIA AMBIENTAL DO ESTADO DE SÃO PAULO (CETESB). Variáveis de qualidade de água. São Paulo, 2009. In: BUZELLI, G. M.; CUNHA-SANTINO, M. B. Análise e diagnóstico da qualidade de água e estado trófico do reservatório de Barra Bonita, SP. Revista Ambiente \& Água, v. 8, n.1, p. 186-205, 2013.

CRISPIM, D. L.; LEITE, R. P.; CHAVES, A. D. C. G.; MARACAJÁ, P. B.; BARBOSA, R. C. A.; CAJÁ, D. F. Diagnóstico ambiental do rio Piancó próximo ao perímetro 
urbano da cidade de Pombal - PB. Revista Brasileira de Gestão Ambiental GVVA, v. 7, n. 3, p. 01 - 06, 2013.

CUIABÁ. Prefeitura Municipal de Cuiabá. Perfil Socioeconômico dos Bairros de Cuiabá ano- 2007. IPDU - Instituto de Planejamento e Desenvolvimento Urbano. Cuiabá: 2007. 126 p.

DELPHA, I.; JUNG. A. V.; BAURES, E.; CLEMENT, M.; THOMAS, O. Impactos da mudança climática na qualidade da água da superfície em relação à produção da água de beber. Revista Interfacehs, v.6, n.2, p.85-107, 2011.

DIAS, A. C.; POTT, A. A influência da mata ciliar na qualidade da água do córrego Bom Jardim-Brasilanida/MS: Estudos iniciais. Periódico Eletrônico Fórum ambiental da Alta Paulista, v.9, n.2, p.1-16, 2013.

ESTEVES, F. A. Fundamentos de Limnologia. 3.ed. Rio de Janeiro: Editora Interciência, 2011. 826p.

FELLENBERG, G. Introdução aos Problemas da Poluição Ambiental. Editora EPU, Ed. da Universidade de São Paulo, 1980. 196p.

FERREIRA, L. H.; ABREU, D. G.; IAMAMOTO, Y.; ANDRADE, J. F. Determinação simples de oxigênio dissolvido em água. Química Nova na Escola, n.19. p.32 - 35, 2004.

FRANCO, F. M.; NOGUEIRA, M. C. J. A.; PINTO JÚNIOR, O. B.; BIUDES, M. S. NOGUEIRA, J. N. Traçado urbano e sua influência no microclima: Um estudo de caso em centro histórico. Revista Eletrônica em Gestão, Educação e Tecnologia Ambiental - REGET, v.9, n.9, p.1916-1931, 2013.

HVITVED-JACOBSEN, T. The Impact of Combined Sewer Overflow on the Dissolved Oxygen Concentration of a River. Water Research, v. 16, p.1099-1105, 1982.

KREISCHER, T. C. V.; GONÇALVES, D. M. M.; VALENTINI, C. M. A. Aspectos hidroambientais do Córrego Barbado em Cuiabá-MT. Revista Holos, ano 28, v.1, p. 86-109, 2012.

MAGALHÃES JUNIOR, A. P. A situação do monitoramento das águas no BrasilInstituições e iniciativas. Revista Brasileira de Recursos Hídricos, v.5, n.3, p.113$115,2000$.

MAITELLI, G. T. (1994). 200p. Uma abordagem tridimensional de clima urbano em área tropical continental: o exemplo de Cuiabá, MT. Tese (Doutorado em Geografia), Faculdade de Filosofia, Letras e Ciências Humanas, Universidade de São Paulo, São Paulo, 1994.

MAZZER, C.; CAVALCANTI, O. A. Introdução à gestão ambiental de resíduos. Revista Infarma, v. 16, n. 11-12, P.676-77, 2004. 
MENEZES FILHO, F. C. M.; AMARAL, D. B. Histórico da expansão urbana e ocorrência de inundações na cidade de Cuiabá-MT. Revista Sociedade e Natureza, v. 26, n.1, p. 159-170, 2014.

PHILIPPI JUNIOR, A.; MARTINS, G. Águas de Abastecimento In: PHILIPPI JUNIOR, A.(ed.). Saneamento, saúde e ambiente: fundamentos para um desenvolvimento sustentável (Coleção Ambiental). Barueri, SP: Manole, cap. 5, p.117-180. 2005.

PINTO, A. L., OLIVEIRA, G. H., PEREIRA, G. A. Avaliação da eficiência da utilização do oxigênio dissolvido como principal indicador da qualidade das águas superficiais da bacia do Córrego Bom Jardim, Brasilândias/MS. Revista Geomae, v.1, n.1, p.6982, 2010.

PORTO, M. F. S.; JUNCA, D. C. M.; GONÇALVES, R. S.; FILHOTE, M. I. F. Lixo, trabalho e saúde: um estudo de caso com catadores em um aterro metropolitano no Rio de Janeiro, Brasil. Caderno de Saúde Pública, v. 20, n. 6, p. 1.503-1.514, 2004.

SHINZATO, M. P.; MARTINS, L. G. B.; SCHALCH, V.; WENDLAND, E. Characteristics of landed material from an abandoned waste dump in Brazil. In: Fourteenth International Waste Management and Landfill Symposium, 2013, Sardinia (Italy). Anais... Sardinia: IWWG, p. 1-8.2013.

SILVA, G. S. ; JARDIM, W. F. Aplicação do método da carga máxima total diária (CMTD) para a amônia no Rio Atibaia, região de Campinas/Paulínia - SP. Revista de Engenharia Sanitária e Ambiental, v.12, n. 2, p.160-168, 2007.

SILVA, V. F.; FERREIRA, A. C.; SILVA, V. F; BARACUHY, J. G. V. Análise de corpos hídricos constituintes do Riacho das Piabas em Campina Grande/PB. Revista Monografias Ambientais, v.13, n.4, p.3460-3466, 2014.

SINGH, R. K.; DATTA, M.; NEMA, A. K. A newsystem for groundwater contamination hazard rating of landfills. Journal of Environmental Management, v. 91, p. 344357, 2009.

SMITH, V.H. \& SCHINDLER, D.W. Eutrophication science: where do we go from here? Trends in Ecology and Evolution, v. 24, p. 201-207, 2009.

SOUZA, D. F.; PINTO, A. L.; MENDES, A. M. S.; OLIVEIRA, G. H. Classificação CONAMA das limitações do uso da água superficial da Lagoa Maior, Três Lagoas/MS. Revista Geonorte, v.3, n.4, p. 771-780, 2012.

TUCCI, C. E. M. Águas urbanas. Estudos Avançados, v.22, n.63, p.97-112, 2008.

VELOZO, R. Caracterização geológico-geotécnica do lixão desativado de São Carlos-SP, com o auxílio da geofísica. 2006. 177 p. Dissertação (Mestrado da Escola de Engenharia de São Carlos)- Universidade de São Paulo, São Carlos. 2006.

VENTURA, R. M. G. Caracterização ambiental e hidrológica da bacia do Córrego Barbado em Cuiabá-MT. 2011. 112p. Dissertação (Mestrado em 
Engenharia de Edificações e Ambiental) - Universidade Federal de Mato Grosso. 2011.

VON SPERLING, M. Introdução à qualidade das águas e ao tratamento de esgotos. Volume 1: Princípios do tratamento biológico de águas residuárias. 3.ed. Belo Horizonte: Departamento de Engenharia Sanitária e Ambiental, UFMG, 2005. $452 \mathrm{p}$.

WETZEL, R. G. Limnology. San Diego: Academic Press, 2001. 1006 p. 